\title{
Faculty Attitudes toward Students with Disabilities in a Public University in Jordan
}

\author{
Bashir Abu-Hamour ${ }^{1}$ \\ ${ }^{1}$ Faculty of Educational Sciences, Department of Counseling and Special Education, Mutah University, Jordan \\ Correspondence: Bashir Abu-Hamour, Faculty of Educational Sciences, Department of Counseling and Special \\ Education, Mutah University, 61710 Al-Karak, Jordan. Tel: 962-775-388-547. E-mail: \\ dr.abuhamourwj@gmail.com
}

Received: October 17, 2013 Accepted: November 19, 2013 Online Published: November 28, 2013

doi:10.5539/ies.v6n12p74 URL: http://dx.doi.org/10.5539/ies.v6n12p74

\begin{abstract}
This study explores the attitudes of higher education (HE) faculty members towards inclusion of students with disabilities at one large public University in Jordan using a survey approach. A total of 170 faculty members completed the survey. The most important findings of this study are: (a) regardless of the academic discipline, the majority of faculty members have positive attitudes toward inclusion of students with disabilities in HE institutions; (b) the majority of the faculty members were not familiar with the disability legislation in Jordan; and (c) the majority of the faculty members were not trained to teach students with disabilities in HE. Implications for future research and practice are discussed in the context of the current disability legislation in Jordan.
\end{abstract}

Keywords: higher education, Jordan, inclusion, disability legislation, students with disabilities

\section{Introduction}

Statistics have shown that there is an increase in the number of students with disabilities who have entered post secondary education. It was estimated that $3-11 \%$ of the entire students population in higher education (HE) institutions have disability that is considered in their university or college admission (National Center for Education Statistics, 2009). Although an accurate estimate of students with disabilities has not been determined in Jordan, it is estimated that around 1\% of the students in HE have disabilities (The Higher Council for the Affairs of Persons with Disabilities, 2007). It is expected that the percentage of students with disabilities in general is higher than this estimation. According to the United Nations (2002), approximately $10 \%$ of the world's population consists of people with disabilities. In Jordan, the documentation of a disability is self-reported by students usually at enrolment and our observation as instructors in HE in Jordan suggest that the number of students with disabilities in higher education is probably under-reported due to the fear of disclosure and the lack of support services. However, the number of the students with registered disabilities in HE in Jordan is increasing. Jordan has recently demonstrated a movement toward a more comprehensive educational system that includes students with disabilities in general education classrooms and in post-secondary education. Widening participation in higher education for students with disabilities has been supported by legislative changes and integrated education practices (Abu-Hamour \& Al-Hmouz, 2013).

\subsection{Disability Legislation in Higher Education}

Due to several governmental initiatives, there are many changes in the educational policy that have resulted in nondiscriminatory practices toward students with disabilities. For example, in the United States (US), the Americans with Disabilities Act of 1990 (ADA) and Section 504 of the Vocational Rehabilitation Act of 1973, are the two federal laws that impact HE (Dona \& Edmister, 2001). These laws protect university students with disabilities from discrimination in admission to and participation in university education. Under the ADA and Section 504, universities must provide reasonable accommodations to make programs accessible to students with documented disabilities. Furthermore, according to the Individuals with Disabilities Education Act (IDEA, 2004), American universities are required to offer students with disabilities the needed accommodations such as making adjustments in locations and scheduling.

Similarly, in Jordan, it is required by law that all HE institutions must provide students with disabilities with all 
accommodations or adjustments to facilitate inclusive teaching practice. In Jordan, we have the "Law on the Rights for Persons with Disabilities for the year of 2007". This law stated in the Article four, Section (B) that 'The Ministries of Education and Higher Education are: providing persons with disabilities with general, vocational, and higher education opportunities in accordance with their disability category through integration; and adopting inclusive education programs between students with disabilities and non-disabled counterparts and implementing these programs within the framework of educational institutions' (The Higher Council for the Affairs of Persons with Disabilities, 2007, p. 4). However, this law is not followed in the real world. For example, Al Hmouze (in press) has recently conducted a study that examined students with disabilities perspectives toward their experiences in a public university in Jordan. The researcher concluded that "although students with disabilities are studying in an integrated HE institution, inclusion is not practiced properly in the university where the research was undertaken". In addition, one major obstacle for students with disabilities in that university was faculty attitudes. Research has shown that students with disabilities are still facing discrimination and negative attitudes towards them by faculty members because of their disability (McLean, Bardwell, Ryan, \& Andrews, 1998; Ryan \& Struhs, 2004). Faculty and student interaction are critical for student success, but it is even more crucial for students with disabilities who struggle with transitioning into a HE environment.

\subsection{Faculty Attitudes toward Students with Disabilities}

It is important to take into consideration that the academic progress of students with disabilities in colleges and universities is significantly affected by the attitudes of faculty members, as well as by their willingness to provide accommodations (Baggett, 1994; Deshler, Ellis, \& Lenz, 1996). Although findings are inconsistent across studies, some reveal that faculty and administrators have, in general, a positive attitude toward students with disabilities and are willing to provide appropriate accommodations (Baggett, 1994; Becker, Martin, Wajeeh, Ward, \& Shern, 2002; Bourke, Strehorn, \& Silver, 2000). On the other hand, students with disabilities attending colleges and universities can face challenges not only due to limited accessibility and delivery of support services but also due to the negative attitudes of peers and faculty members (Duquette, 2000; Tremblay et al., 2008). One of the most vital factors that affect academic achievement and social adjustment of students with disabilities was faculty attitudes (Duquette, 2000; Tremblay et al., 2008). Thus, it is necessary to further explore the factors that affect these attitudes. In addition, some researchers have stated that negative attitudes of faculty members may prevent students with disabilities from using self-advocacy skills and requesting the accommodations to which they are entitled (Dowrick, Anderson, Heyer, \& Acosta, 2005; Johnson, 2006).

Several studies (Kleinsasser, 1999; Rao, 2002; Williamson, 2000) have assessed faculty attitudes toward students with disabilities and the effect of different variables on the attitudes. The variables included gender, age, previous experience in teaching students with disabilities, previous contact with people with disabilities, academic rank of the faculty, academic discipline where the faculty worked, knowledge of legislation, and the type of disability that the students had. Recently, Leyser, Greenberger, Sharoni, and Vogel (2011) conducted a comprehensive literature review to explore the findings regarding the demographic variables that impact faculty attitudes toward students with disabilities in HE. They concluded that: (a) female faculty express more positive attitudes toward students with disabilities than male faculty; (b) faculty with more experience teaching students with disabilities have more positive attitudes toward students with disabilities in HE than those with less experience; and (c) faculty with more training and information about disabilities hold more positive views about students with disabilities than those with less training.

\subsection{Significance of the Study}

Faculty members' attitudes are considered to be a barrier that makes students with disabilities struggle in having a successful experience in education. The main focus of this research is providing guiding information about faculty attitudes toward students with disabilities. One of the most neglected areas from existing research on students with disabilities is the area of faculty attitudes (Rao, 2004). Faculty attitudes and the interactions of faculty with students with disabilities are an integral aspect of student success. The success of any university student, particularly in the academic realm, is to some degree determined by the type and quality of interactions that he or she has with his or her faculty. The relationship between students with disabilities and faculty members could be used to explain the challenges that students with disabilities face in universities and colleges. Several international studies have shown that students with disabilities continue to report negative attitudes toward them by teaching staff including hostility and discrimination (McLean et al. 1998; Ryan \& Struhs, 2004). The integration movement in the Jordanian educational institutions is inhibited by faculty members who are not aware of university policies and the disability legislation. However, to the best of the author' knowledge, no studies have been conducted in higher education in the Arab world or Jordan that has investigated the faculty attitudes toward inclusion of students with disabilities in HE or considered the effect of different demographic 
variables.

\subsection{Purposes of the Study}

The main purpose of this study was to investigate the attitudes of faculty members at a public university in the southern region of Jordan toward inclusion of students with disabilities in HE. Attitudes were examined in relation to selected demographic variables of faculty members. This study addressed the following questions:

Study question 1: To what extent do faculty members favor inclusion of students with disabilities in HE?

Study question 2: How do the demographic characteristic variables of faculty members: (a) gender; (b) academic rank; (c) years of experience in HE; (d) academic discipline; (e) knowledge about the legislation; (f) previous experience with students with disabilities in HE; and (g) training in teaching students with disabilities correlate with the attitudes of faculty members toward inclusion of students with disabilities in a public university in Jordan?

Study question 3: What are the justifications that relate to faculty members' positive or negative attitudes toward inclusion of students with disabilities in a public university in Jordan?

\section{Method}

This study was conducted in a large public university in the southern region of Jordan. The target population for this study was all full-time faculty members in the university. This university has 550 faculty members in 12 colleges. 20,000 undergraduate and graduate students enrolled in the university when the study was conducted. Of that population, 52 students (less than $1 \%$ ) were receiving documented disability support services.

\subsection{Participants}

A total of 550 surveys were distributed to faculty members and 176 (32\% response rate) were returned. However, 6 were excluded from these analyses because they failed to complete one or more sections of items. Table 1 provides an overview of the demographic characteristics of the selected sample $(n=170)$ on four demographic variables (i.e., gender, faculty rank, academic discipline, and years of teaching experience). As presented in Table 1 , of the 170 participants in the study, $57.1 \%$ were male and $42.9 \%$ were female; in terms of rank, $14.7 \%$ indicated that they were full professor, $30 \%$, associate professor, and 55.3\%, assistant professor. Most major colleges in the university participated in the study. These colleges include Science, Engineering, Medicine, Commerce, Arts, and Education. These colleges were combined into humanities and science colleges for the purpose of this study. Most of the participants had 1-5 or 6-15 years of teaching experience.

Table 1. Demographic characteristics of faculty members

\begin{tabular}{|c|c|c|}
\hline Variable & $\mathbf{N}$ & $\%$ \\
\hline \multicolumn{3}{|l|}{ Gender } \\
\hline Male & 97 & 57.1 \\
\hline Female & 73 & 42.9 \\
\hline \multicolumn{3}{|l|}{ Rank } \\
\hline Professor & 25 & 14.7 \\
\hline Associate Professor & 51 & 30.0 \\
\hline Assistant Professor & 94 & 55.3 \\
\hline \multicolumn{3}{|l|}{ Academic Discipline } \\
\hline Humanities Colleges & 119 & 70.0 \\
\hline Scientific Colleges & 51 & 30.0 \\
\hline \multicolumn{3}{|l|}{ Years teaching } \\
\hline $1-5$ & 81 & 47.7 \\
\hline $6-15$ & 73 & 42.9 \\
\hline $15+$ & 16 & 9.4 \\
\hline
\end{tabular}

Note: $n=170$.

\subsection{Procedures}

A letter from the author was sent to the University Research Office that supplemented by the survey and the study purpose to request approval for the study. When approved, the Human Resources Office in the university provided the researcher with all of the descriptive information for faculty members in all colleges. Next, deans in 
all university colleges were contacted to facilitate the researchers' job. Hard copies of surveys were sent to all faculties through the internal mail system at the university. To ensure anonymity, no identifying information was included on the surveys. Two follow-up requests were sent via e-mail to all faculties, requesting that they complete and return surveys. Completed forms were returned to one mailbox and later collected by the researcher. All data were collected during November of 2012.

A cover letter explaining the survey purposes; the terms of disability and inclusion; and the estimated time of filling it out was presented in the beginning of the study. For the purpose of this study, disability was defined as "a condition or function judged to be significantly impaired relative to the usual standard of an individual or group. The term is used to refer to individual functioning, including learning disability, physical impairment, sensory impairment, intellectual impairment, mental illness, and various types of chronic disease". Inclusion was defined as "a process intended to respond to students' diversity by increasing their participation and reducing exclusion within and from education. It is related to the attendance, participation and achievement of all students, especially those with disabilities who are excluded or at risk of being marginalized".

\subsection{Instrument}

To develop the study's instrument, the researcher reviewed prior published instruments used to assess faculty attitudes. The instrument developed by Thompson, Bethea, and Turner (1997) was particularly informative. This instrument asked the participants to answer questions pertaining to the study variables (e.g., demographic characteristics, inclusion preference, knowledge about the legislation, previous experience with students with disabilities, and training in teaching students with disabilities in HE). The answers were "yes" or "no". In addition, the survey included one pen-ended question that asked the faculty to justify their attitudes for inclusion. In terms of validity, the survey was sent to ten reviewers who are experts in the field of disabilities and HE to examine and critique the constructs of the instrument. Next, a pilot study was carried out with 17 faculty members about one month before the survey was sent to the faculty from different colleges on campus. Suggestions were carefully incorporated into the final instrument to enhance validity. The Cronbach alpha coefficient of internal consistency reliability for the survey was 0.92 .

\subsection{Analyses}

The Statistical Package for the Social Sciences (SPSS), version 17.0, was used to analyze the data. Responses were analyzed using descriptive statistics and Chi-square tests. In terms of the open-ended question, the responses were analyzed through a process of open and focused coding from the author and two graduate research assistants. Each response was read independently and coded openly, creating a basic scheme of codes. The team then met and constructed a focused scheme that included all the insights of the first reading. The process of multiple readings with multiple readers increased the credibility of our analyses by allowing for triangulation of our analytic readings (Marshall \& Rossman, 2006).

\section{Results}

About $85.9 \%(n=146)$ of the faculty members were confident that students with disabilities should be educated in HE institutions in Jordan, while $14.1 \%(n=24)$ did not favor inclusion of students with disabilities in HE. Factors that were correlated with the participants' opinions toward inclusion of students with disabilities in HE are discussed in the following sections.

\subsection{Gender}

Of the total number of participants, $57.1 \%$ (97) were males and 42.9 (73) were females. A $2 \times 2$ chi-square test conducted to check whether there was a statistically significant difference between males and females in terms of the participants' opinions toward inclusion of students with disabilities in HE and yielded a significant difference $\chi^{2}(1)=7.82, p=.003$. A higher percentage of male participants presented negative attitudes regarding inclusion of students with disabilities in HE (83.3\%) versus the female participants (16.7\%).

\subsection{Academic Rank}

Of the total number of participants, $55.3 \%$ (94) were assistant professors, $30 \%$ (51) were associate professors, and $14.7 \%(25)$ were full professors. A $2 \times 3$ chi-square test indicated that the relationship between academic rank and participants' opinions toward inclusion of students with disabilities in HE was significant $\chi^{2}(2)=24.64$, $p<.001$. Specifically, faculty members who had an assistant professor rank presented a higher percentage of positive attitudes toward inclusion of students with disabilities in HE (65.2\%), compared to (24.4\%) and (10.4\%) for associate professor and full professor respectively. 


\subsection{Years of Teaching Experience in HE}

Of the total number of participants, $47.7 \%$ (81) had 1-5 years of experience; $42.9 \%$ (73) had 6-15 years of experience; and 9.4\% (16) had more than 15 years of experience. A $2 \times 3$ chi-square test indicated that the relationship between years of teaching experience and participants' opinions toward inclusion of students with disabilities in HE was significant $\chi^{2}(2)=36.62, p<.001$. A higher percentage of positive attitudes toward inclusion of students with disabilities in HE (57.8\%) was presented by faculty members who had 1-5 years of experience compared to (37.8\%) and (4.4\%) for 6-15 and more than 15 years of experience respectively.

\subsection{Academic Discipline}

Of the total number of participants, $70 \%$ (119) were from humanities discipline colleges and $30 \%(51)$ were from scientific discipline colleges. A $2 \times 2$ chi-square test indicated that the relationship between academic discipline of participants and attitudes toward inclusion of students with disabilities in HE was not significant $\chi^{2}(1)=.33$, $p=.377$.

\subsection{Knowledge about the Legislation}

Of the total number of participants, $82.9 \%$ (141) did not have a knowledge of the "Law on the Rights for Persons with Disabilities for the year of 2007" in Jordan and 17.1\% (29) knew about this Law. A $2 \times 2$ chi-square test indicated that the relationship between knowledge of the law and the participants' attitudes toward inclusion of students with disabilities in HE was not significant $\chi 2(1)=.41, p=.381$.

\subsection{Previous Experience with Students with Disabilities in $H E$}

Of the total number of participants, $84.1 \%$ (143) had an experience of teaching students with disabilities in HE and $15.9 \%$ (27) did not teach students with disabilities in HE. A $2 \times 2$ chi-square test indicated that the relationship between previous experience with students with disabilities in HE and the participants' attitudes toward inclusion of students with disabilities in HE was not significant $\chi 2(1)=.51, p=.325$.

\subsection{Training on Teaching Students with Disabilities in $\mathrm{HE}$}

Of the total number of participants, $89.4 \%$ (152) were not trained to teach students with disabilities in HE and $10.6 \%$ (18) were trained in teaching students with disabilities in HE. A $2 \times 2$ chi-square test indicated that the relationship between training in teaching students with disabilities in HE and the participants' attitudes toward inclusion of students with disabilities in HE was not significant $\chi^{2}(1)=.10, p=.483$.

\subsection{Participants' Justifications for Their Attitudes toward Inclusion of Students with Disabilities in HE}

Answers to the open-ended question that asked participants to justify their positive or negative attitudes toward inclusion of students with disabilities in HE were coded. The main themes for faculty members who were in favor of inclusion of students with disabilities in HE were: (a) the faculty member taught students with disabilities and they were able to fulfill the course requirements similar to students without disabilities; (b) according to the law, students with disabilities have the right to be educated in Jordanian universities; and (c) providing appropriate HE experience for students with disabilities will increase their chance to be successful in life. On the other hand, the main themes for faculty members who had negative attitudes toward inclusion of students with disabilities in HE were: (a) faculty members have busy schedules and they cannot provide special treatments for students with disabilities; (b) students with disabilities will not be able to fulfill the studying requirements at the university programs; and (c) faculty members do not have sufficient knowledge or training to make appropriate accommodations for students with disabilities.

\section{Discussion}

The main purpose of this investigation was to explore faculty attitudes toward inclusion of students with disabilities in HE considering various demographic variables. The most important findings of this study are: (a) regardless of the academic discipline, the majority of faculty members have positive attitudes toward inclusion of students with disabilities in HE institutions; (b) female faculty express more positive attitudes toward students with disabilities than male faculty; (c) faculty members who had an assistant professor rank presented more positive attitudes toward students with disabilities than associate professors and professors; (d) faculty members with fewer years of experience presented more positive attitudes toward students with disabilities than those with over five years of experience in HE; (e) the majority of the faculty members were not familiar with the disability legislation in Jordan; and (f) the majority of the faculty members were not trained to teach students with disabilities in HE. In addition, answers to the open-ended question indicated that some of the faculty members were motivated to the inclusion of students with disabilities because they had had a positive previous experience with students with disabilities in HE. On the other hand, other faculty members were skeptical about the ability 
of students with disabilities to fulfill the course requirements or even their individual ability to teach and make appropriate accommodations for students with disabilities.

Similar to reports in previous studies (Baggett, 1994; Becker et al., 2002; Bourke et al., 2000; Leyser et al., 2011), most faculty expressed positive attitudes towards inclusion of students with disabilities in HE. In addition, consistent with previous research (e.g., Baggett, 1994), gender comparisons in this investigation indicated that female faculty have more positive attitudes than male faculty. Furthermore, the findings revealed that faculty at a lower rank with fewer HE teaching experiences had more positive attitudes regarding the inclusion of students with disabilities in HE.The most logical explanation for these findings is that schools and universities are now including courses and that address students with disabilities and the inclusion movement.

One unfortunate finding is that the majority of the faculty members have little knowledge about the "Law on the Rights for Persons with Disabilities'for the year of 2007" in Jordan. Specifically, faculty members are not aware of their legal responsibilities toward students with disabilities. Unfortunately, even though this law has passed since 2007, it is not known by many faculty members in Jordan. It would be easy to think that legislation in itself has created an environment that can accommodate the educational needs of students with disabilities in Jordan but this is not true. The law of education and higher education for students with disabilities needs to be enforced in Jordan. Most of the students with special needs enroll in the regular education system in Jordan without being provided adequate educational support. The practice of the regular educational system is reflected in the higher educational system as well. Results indicated that the faculty members had concerns about their ability to teach and accommodate students with disabilities. Thus, faculty must be trained to teach and provide specific accommodations for students with disabilities. The faculty professional development should be prepared to meet the needs of students with disabilities in all Jordanian universities and community colleges. Disability service directors and their staff should have a major responsibility for the planning, coordination, implementation and evaluation of this professional development.

\subsection{Implications and Future Research}

The success of inclusion in HE is partially depending on the attitudes of faculty members. This in turn, would require educational institutions that to inform their faculty members about the best practices of inclusion that would lead to successful experiences for students with disabilities in HE. In Jordan, HE institutions should review their decisions, policies, and practices toward students with disabilities. The policies and legal protections of students with disabilities need to be better understood, accepted, and implemented at all universities and community colleges. It is important that policy makers and leaders work together to make the necessary plans for increasing knowledge and application of disability legislation, specifically, the ones that are related to students with disabilities in education and HE institutions. A national effort is required to make faculty aware of their legal responsibilities toward students with disabilities in HE.

Future research should focus on professional development of faculty members across Jordan that include high quality training on all related issues to students with disabilities in HE. For example, disability legislation, teaching strategies, and assessment accommodations should be addressed in this training. Several strategies for delivering training activities are available. Scott and Gregg (2000) suggested three approaches: (a) large group in-service as a tool for general awareness, (b) small group workshops allowing more in-depth information on the topic and (c) individual follow-up to assist faculty to create appropriate plans for individual students. In addition, the flexibility of an online training program could provide the faculty members with a convenient way of getting the information about students with disabilities. Future research should also focus on the disability service directors and their role in educating the faculty members about students with disabilities. Finally, the relationships between legal accountability, training about students with disabilities in HE, and faculty attitudes should be explored further in future research.

\subsection{Limitations}

This study has several limitations. First, the sample comes from one institution in Jordan, and therefore the findings do not necessarily apply to other Jordanian universities. Additional studies are recommended in other institutions of HE in Jordan and the Arab world. Second, the reported findings of this investigation were mainly based on self-report survey by faculty. This study may be validated by investigating the faculty attitudes using interview methods. Finally, the study results may be affected by the fact that some of the faculty members expressed positive attitudes because they thought that was socially desirable, but they did not actually feel that way. 


\section{References}

Abu-Hamour, B., \& Al-Hmouz, H. (2013). Special Education in Jordan. European Journal of Special Needs Education. http://dx.doi.org/10.1080/08856257.2013.859820

Al Hmouz, H. (in press). Students with disabilities experiences in a public university in Jordan. International Journal of Special Education.

Baggett, D. (1994). A study of faculty awareness of students with disabilities. Paper presented at the annual meeting of the National Association for Developmental Education, Kansas City, MO.

Becker, M., Martin, L., Wajeeh, E., Ward, J., \& Shern, D. (2002). Students with mental illness in a university setting: Faculty and student attitudes, beliefs, knowledge, and experiences. Psychiatric Rehabilitation Journal, 25, 359-367. http://dx.doi.org/10.1037/h0095001

Bourke, A. B., Strehorn, K. C., \& Silver, P. (2000). Faculty members' provision of instructional accommodations to students with LD. Journal of Learning Disabilities, $33(1), 2$. http://dx.doi.org/10.1177/002221940003300106

Deshler, D. D., Ellis, E. S., \& Lenz, B. K. (1996). Teaching adolescents with learning disabilities: Strategies and methods. Denver, CO: Love Publishing.

Dona, J., \& Edmister, J. H. (2001). An examination of community college faculty members' knowledge of the Americans with Disabilities Act of 1990 at the fifteen community colleges in Mississippi. Journal of Postsecondary Education and Disability, 14, 91-103.

Dowrick, P. W., Anderson, J., Heyer, K., \& Acosta, J. (2005). Postsecondary education across the USA: Experiences of adults with disabilities. Journal of Vocational Rehabilitation, 22, 41-47.

Duquette, C. (2000). Experiences at university: Perceptions of students with disabilities. The Canadian Journal of Higher Education, 30(2), 123-142.

Individuals with Disabilities Education Improvement Act. (2004). U. S. Department of Education, Public Law, 108-446. Washington, DC.

Johnson, A. L. (2006). Students with disabilities in postsecondary education: Barriers to success and implication to professionals. VISTAS Online. Retrieved from http://counselingoutfitters.com/Johnson.htm

Kleinsasser, C. L. (1999). College faculty's and staff's attitude and knowledge concerning learning disabilities: Implications for staff development (Doctoral dissertation, University of South Dakota, 1999). Dissertation Abstracts International, 60, 07A.

Leyser, Y., Greenberger, L., Sharoni, V., \& Vogel, G. (2011). Students with disabilities in teacher education: Changes in faculty attitudes toward accommodations over ten years. International Journal of Special Education, 26(1), 162-174.

Marshall, C., \& Rossman, G. B. (2006). Designing Qualitative Research (4th ed.). Thousand Oaks, CA: Sage.

McLean, P., Bardwell, M., Ryan, J., \& Andrews, J. (1998). A hidden disability: University students with mental health conditions. Melbourne: University of Melbourne.

National Center for Education Statistics (NCES). (2009). Number and Percentage Distribution of Students Enrolled in Postsecondary Institutions, by Level, Disability Status, and Selected Student and Characteristics: 2003-04 and 2007-08. Digest of Education Statistics. Retrieved from November 20, 2011 http://nces.ed.gov/programs/digest/d09/tables/dt09_231.asp

Rao, M. S. (2002). Students with disabilities in higher education: Faculty attitudes and willingness to provide accommodations (Unpublished doctoral dissertation, University of Arkansas, Fayetteville).

Rao, S. (2004). Faculty attitudes and students with disabilities in higher education: A literature review. College Student Journal, 38(2), 191-198.

Ryan, J., \& Struhs, J. (2004). University education for all? Barriers to full inclusion of students with disabilities in Australian universities. International Journal of Inclusive Education, 8(1), 73-90. http://dx.doi.org/10.1080/1360311032000139421

Scott, S. S., \& Gregg, N. (2000). Meeting the evolving education needs of faculty in providing access for college students with LD. Journal of Learning Disabilities, 33, 158-67. http://dx.doi.org/10.1177/002221940003300204 
The Higher Council for the Affairs of Persons with Disabilities. (2007). Law on the Rights of Persons with Disabilities. Amman, Jordan.

Thompson, A. R., Bethea, L., \& Turner, J. (1997). Faculty knowledge of disability laws in higher education: A survey. Rehabilitation Counseling Bulletin, 40, 166-181.

Tremblay, P. F., Harris, R., Berman, H., MacQuarrie, B., Hutchinson, G. E., Smith M. A., . . . Dearlove, K. (2008). Negative social experiences of university and college students. Canadian Journal of Higher Education, 38(3), 57-75.

United Nations. (2002). The United Nations and disabled persons: The first 50 years. Retrieved from http://www.un.org/esa/socdev/enable/dis50y50.htm

Williamson, P. T. (2000). Attitudes of the Troy State University Dothan faculty toward students with disabilities (Doctoral dissertation, Auburn University. 2000). World Cat, OCLC: 44857670.

\section{Copyrights}

Copyright for this article is retained by the author(s), with first publication rights granted to the journal.

This is an open-access article distributed under the terms and conditions of the Creative Commons Attribution license (http://creativecommons.org/licenses/by/3.0/). 